\title{
Gambling and ageing: less illusion but more risk
}

\author{
Maylis Fontaine ${ }^{1 \star}$ (D), Valérie Le Floch ${ }^{1}$ and Céline Lemercier ${ }^{1}$ \\ ${ }^{1}$ CLLE, Université de Toulouse, CNRS, UT2J, Toulouse, France \\ ${ }^{\star}$ Corresponding author. Email: maylis.fontaine@univ-tlse2.fr
}

(Accepted 27 April 2021; first published online 3 June 2021)

\begin{abstract}
Seniors are a population of concern due to exposure to both increasing gambling venues and powerful age-specific risk factors. There has been only limited research on this population so far, but studies conducted among younger adults suggest that the illusion of control is a key factor, leading players to develop strategies that increase their risk-taking in gambling. Time perspective (TP) is a good indicator of risky behaviours in a number of different areas, including health and the environment. In the present study, we sought to identify the age-specific cognitive mechanisms underlying gambling behaviour in normal ageing. We asked 115 emerging adults (mean age $=20.86$ years), 86 young adults $($ mean age $=30.59), 82$ middle-aged adults (mean age $=44.57)$ and 108 seniors (mean age $=65.19)$ to play an online game. We rated their illusion of control, risk-taking and TP. Analysis revealed that seniors took more risks and had less illusion of control than younger adults. The fatalistic-present TP positively influenced the illusion of control, such that perceiving the present as being determined by uncontrollable forces increased the perceived level of control. Finally, we found an influence of age on TP. These results suggest that seniors constitute a specific population in terms of gambling-related cognitions and behaviours. Including TP in risky behaviour assessments would allow the development of tailor-made preventive measures.
\end{abstract}

Keywords: gambling; ageing; time perspectives; illusion of control; risk-taking

\section{Introduction}

Gambling is a worldwide and cross-cultural recreational activity with growing importance (Binde, 2013; Abbott et al., 2018). For example, in the United States of America (USA), between 76.9 and 82.2 per cent of the general population report having gambled in the past year (Calado and Griffiths, 2016). In Canada, it is between 66.6 and 82.9 per cent depending on the province (Hilbrecht et al., 2020), in Australia, 63.9 per cent (Dowling et al., 2016) and in Asia, between 41.8 and 81.1 per cent (Calado and Griffiths, 2016). Internationally, the rate of problem gambling ranges from 0.12 to 5.8 per cent, and in Europe from 0.12 to 3.4 per cent (Calado and Griffiths, 2016). More specifically, in France, where 47.2 per cent of the population reported gambling activity in 2019, the prevalence

(C) The Author(s), 2021. Published by Cambridge University Press. This is an Open Access article, distributed under the terms of the Creative Commons Attribution licence (http://creativecommons.org/licenses/by/4.0/), which permits unrestricted re-use, distribution, and reproduction in any medium, provided the original work is properly cited. 
of problem gambling is 2.9 per cent (Costes et al., 2020). While French households are spending less money on leisure in general (9.6\% of budget in 2000 versus $8.3 \%$ in 2015), they are spending more money on gambling (8.3\% of leisure budget in 2000 versus $10 \%$ in 2015), that is, $€ 9,713$ million for the entire population in 2015 (Observatoire Des Jeux, 2016). Finally, according to the National Institute of Statistics and Economic Studies (INSEE, 2016), the largest consumers of gambling in France are seniors aged 55-64 years. Gambling has attracted considerable attention from researchers since the 2000s. In addition to a large amount of work on the general population, much research has focused on adolescents and young people, who are considered a vulnerable population. However, seniors are vulnerable too (Wainstein et al., 2008; Tse et al., 2012; Subramaniam et al., 2015). While youth are considered an at-risk population when participating in particular activities, such as gambling, due in part to their lack of resources, older adults may also be at risk due to diminished resources (Gibbs Van Brunschot, 2009). This large consumer population therefore merits specific research, although there has been very little to date (Skinner and Turner, 2018). After reviewing the main findings from studies conducted with seniors (for reviews, see Subramaniam et al., 2015; Luo and Ferguson, 2017; Guillou Landreat et al., 2019), we describe the gambling processes in terms of illusion of control (Langer, 1975), a key factor that influences gambling behaviour across the general population, regardless of age. Based on decision-making research, we first set out to show that age influences attitudes towards risk-taking, an observable indicator of gambling behaviour. We then consider illusion of control and the possible age-related deterioration in decision-making processes that leads to risk-taking. We end by introducing a new gambling variable, namely time perspectives (TPs), which may be a predictor of gambling behaviour.

Seniors from many different cultures display positive attitudes towards gambling, which they regard as an ordinary and safe form of entertainment (Tse et al., 2012; Luo and Ferguson, 2017). Gambling participation rates among seniors from different cultures range from 26.6 to 56.2 per cent (Luo and Ferguson, 2017). In France, 49.3 per cent of 55-64 year olds and 37.6 per cent of 65-75 year olds gambled in 2019 (Costes et al., 2020) compared to 44.1 and 31 per cent, respectively, in 2010 (Costes et al., 2011). In both the USA and Canada, where casino gambling is legal, seniors are increasingly spending their leisure time in these venues (McNeilly and Burke, 2001). The main reason for seniors' growing attraction to casinos is that they provide an opportunity to break with social isolation and boredom. Older people's urge to gamble is triggered by various social stimuli such as advertisements for, among others, lotteries and casinos, presented as attractive and promising places (Medeiros et al., 2015; Luo and Ferguson, 2017). Seniors perceive gambling in all its forms as 'something therapeutic, analgesic, rejuvenating, motivational, liberating, and bonding, as opposed to being gambling per se' (Tira and Jackson, 2015: 26). These perceptions favour the development and maintenance of gambling problems among seniors. Not perceiving gambling as gambling is a risk factor because its dangers are then ignored, and when the practice is problematic, preventive actions are ignored as well (Hirsch, 2000). It should be noted, however, that recreational gambling among older adults is associated with positive outcomes in terms of socialisation, health, wellbeing and even cognitive stimulation (Desai et al., 2004; Hagen et al., 2005). In contrast, problem gambling behaviours 
have been associated with elevated levels of anxiety and loneliness (Kerber et al., 2008; Grant et al., 2009). Seniors can perceive gambling as a way of reducing negative mood states (Parke et al., 2018). Indeed, when the main motivation for gambling is to escape anxiety and loneliness, the likelihood of experiencing gambling-related harm is greater (van der Maas et al., 2017; Parke et al., 2018; Granero et al., 2020).

The rate of problem or pathological gambling among seniors around the world ranges from 2 to 10.4 per cent (Luo and Ferguson, 2017). In France, 3.8 per cent of gamblers aged 55-64 and 3.5 per cent of gamblers aged 65-75 are problem gamblers (Costes et al., 2020). Older adult populations have lower prevalence rates of problem gambling than their younger counterparts but it is a significant problem in this demographic (Pietrzak et al., 2005; Subramaniam et al., 2015; Luo and Ferguson, 2017), particularly because of the seriousness of the consequences. Older gamblers (i.e. over 60 years of age) have greater difficulty recovering from the health complications, psychological and social problems, and financial difficulties resulting from problem gambling (Ariyabuddhiphongs, 2012). Older people who engage in excessive gambling more often go undetected and are less likely to seek help. Fixed incomes, isolation, inactivity and failing health make them extremely vulnerable to gambling-related problems (Subramaniam et al., 2015; Granero et al., 2020). They therefore constitute a more vulnerable population in terms of financial fragility and risk of suicide than other age groups (Pittet et al., 2014), especially since pathological gambling is the most common behavioural addiction among older adults (Guillou Landreat et al., 2016).

In view of these statistics and the vulnerability of older people, it is important to study the effect of age on gambling behaviours, if we are to understand and identify the profiles of older gamblers and, ultimately, reduce risks more effectively through appropriate primary prevention. Given the lack of empirical studies of gambling mechanisms among seniors (Tse et al., 2012), in order to understand the specific behaviours of gamblers over 55 years, we applied current reference models of gamblers and knowledge of gambling relating to the general population, postulating the role of illusion of control as a key factor.

Expectation of a personal success greater than the objective probability, the so-called illusion of control (Langer, 1975), plays a major role in the general population's gambling behaviour (Keren and Wagenaar, 1985; Blaszczynski and Nower, 2002; Barrault and Varescon, 2012). To our knowledge, illusion of control has not been studied with seniors in gambling. Illusion of control is influenced by various situational factors (Presson and Benassi, 1996; Stefan and David, 2013). Sequence of outcomes is particularly relevant here, which is the order in which losses and gains occur. In some cases, the player faces a series of losses followed by gains. In other cases, the opposite is true. When Langer and Roth (1975) manipulated a sequence of 30 trials (15 gains and 15 losses in total) under three experimental conditions (descending, ascending, random), results showed that participants exhibited a greater illusion of control in a descending order (first gains then losses) than in an ascending one. However, another study (Ejova et al., 2013) found a stronger illusion of control in an ascending condition (first losses then gains), which the authors attributed to a false impression of learning an appropriate strategy. An increasing success rate, although objectively independent of the individual's 
actions, may indeed lead gamblers to believe that they have learned a strategy to control the uncontrollable (Matute, 1995). These contradictory findings may arise from a measurement problem identified by Langer (1975). As illusion of control covers several aspects (belief in a degree of skill, control over the game, power of prediction, negation of chance), a wide variety of measures have been used in the literature, each relating to only one of these dimensions (Goodie et al., 2019). Focusing on the risk-taking associated with, for example, the sequence of outcomes is a means of objectifying gambling behaviour.

According to Rogers' (1998) definition, gambling is a situation in which the gambler decides to run the risk of losing, with the hope of winning with a certain probability. Widely investigated in the literature on decision making (for a review about ageing, see Löckenhoff, 2018), based on the work by Kahneman and Tversky (1979), risk-taking has only been studied in a limited number of studies of gambling, but they were primarily interested in the effect of age. Mather et al. (2012) studied risk-taking among adults aged 55-89 years in relation to the certainty effect (Kahneman and Tversky, 1979), where individuals perceive certain outcomes (i.e. 0 or $100 \%$ ) as having more weight in their decision than uncertain outcomes (probabilities between 0 and 100\%). Associated with the desirability of the outcome (gains being desirable and losses undesirable), the certainty effect predicts risk aversion when it concerns gains, and a search for risk when it concerns losses. Older adults are more sensitive than younger ones to the certainty effect for losses (Mather et al., 2012). They are thought to be more averse to loss than young people, owing to an exacerbation with age of the certainty effect in the area of losses but not in the area of gains. These results were corroborated by Tymula et al. (2013), who also found an exacerbated certainty effect with age in the gains domain despite preserved intellectual abilities. Older adults choose riskier options than younger when it concerns potential gains (Pachur et al., 2017). These findings from the decisionmaking literature suggest that attitudes towards risk change with age. In a specific context (with the Iowa Gambling Task as the measure of decision making), older people have impaired decision making despite their intellectual abilities (Denburg et al., 2005; Fein et al., 2007; Beitz et al., 2014). These age-related changes in decision making under risk would be influenced by different factors such as affect (Pachur et al., 2017) or motivation (Strough et al., 2015). Other factors can be considered, such as TP.

The gambling habits of seniors (over 55 years) are strongly impacted by life events such as retirement, health problems, finance, leisure, social relationships and psychological health (Poupard, 2013; Giroux et al., 2016). These life experiences influence individuals' relationship to time, just as their relationship to time can influence their perception of these experiences. It therefore seems appropriate to articulate gambling behaviours with TPs as defined by Zimbardo and Boyd (1999) (for an overview, see Stolarski et al., 2015).

According to Zimbardo and Boyd (1999), TPs 'refer to the dynamic relationships, both emotional and cognitive, that a person has with his or her past, present registration and future projections' (Gana et al., 2013: 50). Individuals' behaviour revolves around temporal dimensions that are sensitive to context. Their relationship to the past is either mainly positive or mainly negative. Their relationship to the present depends on whether their attitude is hedonistic (perception of the 
ephemerality of the present moment that we want to take advantage of) or fatalistic (perception of events as predetermined and a more or less severe form of resignation). Their relationship to the future depends on anticipation and investment as a function of other temporalities. A negative past and fatalistic present have a negative effect on the life satisfaction of older people, whereas a hedonistic present has a positive effect (Gana et al., 2013). The work of Gana et al. (2013) suggests that the perception of the environment has a more decisive influence than the actual reality of that environment on behaviours. For example, a TP with a dominant fatalistic present means that events are regarded as predetermined and unavoidable. This perceived lack of control leads individuals to adopt a wait-and-see, passive or even resigned posture. Feeling that an event has an external cause and that a situation cannot be controlled prevents individuals from initiating actions.

TPs are a good indicator of risky behaviours in different areas, including environment and health. Focusing on future TP, Demarque et al. (2011) established a link between individuals' relationship to time and their social belonging and social support, which jointly influence future projections in terms of environmental behaviour. Individuals who belong to environmental groups or have high perceived social support project themselves into a longer-term future and adjust their current behaviours according to their self-reported personal involvement in environmental issues, such as designing an action related to the environment.

Going back to gambling research, Hodgins and Engel (2002) showed that pathological gamblers have significantly more hedonistic and fatalistic-present TPs than social gamblers. Contrary to expectations, however, the former did not have shorter future TP. According to the authors, pathological gamblers focus more on the pleasure of the present moment, without considering the impact of their behaviour on the future, as they do not believe they can influence this future. In adolescent boys, the fatalistic present perspective predicts gambling frequency and the future perspective is negatively related to problem gambling (Donati et al., 2019). To our knowledge, only these two studies have examined gambling in relation to TP. Research on TP, however, has more broadly investigated the effects of age.

Contrary to the preconceived idea that older people are more oriented towards the past, ageing seems to foster the predominance of the present (Cameron, cited by Nuttin, 1979). More precisely, ageing is associated with an increased fatalistic present time orientation (Rönnlund et al., 2017). If we compare this predominance of the present in older people (Cameron, cited by Nuttin, 1979) with the predominance of the present in pathological gamblers (Hodgins and Engel, 2002), we can legitimately ask whether it can explain the finding of Wainstein et al. (2008) regarding the increasing prevalence of pathological gambling in older people. Other TPs may nuance this effect in non-pathological gamblers. TPs may underpin the functional development of psychological adaptability (Kruger et al., 2008). Acting as 'a cognitive style that influences attitudes and behaviours' (Epel et al., 1999: 592), TPs can help to understand the risk-taking component of gambling behaviour among seniors in refining current models of illusion of control.

The main purpose of the present study was to explore the age-related specifics in terms of gambling-related illusion of control, risk-taking and TP. We expected to find age-related differences on these different variables. The age of seniors in the literature is not consensual, the lower boundary ranging from 50 to 70 (for a review, 
see Guillou Landreat et al., 2019). The World Health Organization (2015) recognises that old age should be defined by new roles and different factors other than years. With many changes occurring in life as early as age 55 (Giroux et al., 2016) and many gambling studies setting the lower age boundary at 55, the seniors in this study are people over 55 years old. As we have indicated, there has so far been little work to investigate the effects of ageing and TPs on gambling behaviour. We therefore specifically addressed the effect of age on illusion of control and risk-taking, as well as the possible mediating effect of TPs on these influences. As there is no consensus in the literature, we began by investigating the effect of the sequence of outcomes on participants' illusion of control, asking whether this effect increases with an ascending sequence (Ejova et al., 2013) or with a descending one (Langer and Roth, 1975). We then tested whether the sequence of outcomes also has an effect on risk-taking. We expected seniors to take more risks than young people in a loss situation (i.e. ascending sequence: first losses, then gains).

\section{Method}

\section{Participants}

Participants were recruited through call for volunteers announcements posted on students, retirees and gamblers Facebook groups. No financial compensation nor any recompense was offered in exchange for participation. Data were collected online, using the Qualtrics platform, between 29 January 2017 and 31 March 2017.

Six hundred and eighty-nine people took part in the study; 399 fully responded to the online protocol (socio-demographic questionnaire, game, and illusion of control and TP questionnaires). We excluded eight participants as they left the game stage before the first round, leaving data from 391 participants; 47 per cent gamble at least occasionally (for gambling habits by age, see Figure 1). Table 1 shows the participants' socio-demographic information. Participants were divided into eight groups according to age (emerging adults, young adults, middle-aged adults, seniors) and sequence of outcomes (ascending: losses then gains versus descending: gains then losses).

\section{Materials}

Game

Participants were invited to play an online game of chance, in which they had to bet in order to win as many points as possible (see the Appendix). It took the form of a set of cards arranged in four piles, each with a different probability of winning and a different number of points in the event of a win. Inspired by the bets in French roulette, the first pile offered 18/37 chances of recovering the initial stake, the second 12/37 chances of winning double the stake, the third 3/37 chances of winning 11 times the stake and the fourth $1 / 37$ chances of winning 35 times the stake. Participants had to choose the pile on which they wanted to bet and the size of the stake, depending on how many points they had left. They had an initial capital of 100 points (as in Martinez et al., 2004). As this capital fluctuated, it was displayed in the top left-hand corner of the screen during each round. Based on research 
Table 1. Participants' socio-demographic characteristics

\begin{tabular}{|c|c|c|c|c|}
\hline & \multicolumn{4}{|c|}{ Age group } \\
\hline & $\begin{array}{c}\text { Emerging } \\
\text { adults } \\
\text { (18-25 years) }\end{array}$ & $\begin{array}{l}\text { Young } \\
\text { adults } \\
\text { (25-38 } \\
\text { years) }\end{array}$ & $\begin{array}{l}\text { Middle-aged } \\
\text { adults } \\
\text { (38-55 years) }\end{array}$ & $\begin{array}{c}\text { Seniors } \\
\text { (55 years and } \\
\text { over) }\end{array}$ \\
\hline \multirow[t]{2}{*}{ Mean age (SD) } & $20.86(1.88)$ & $30.59(3.75)$ & $44.57(5.02)$ & $65.19(6.95)$ \\
\hline & \multicolumn{4}{|c|}{ Frequencies } \\
\hline Males & 19 & 25 & 19 & 46 \\
\hline Females & 96 & 61 & 63 & 62 \\
\hline All participants & 115 & 86 & 82 & 108 \\
\hline \multicolumn{5}{|c|}{ Sequence of outcomes: } \\
\hline Descending & 68 & 41 & 43 & 61 \\
\hline Ascending & 47 & 45 & 39 & 47 \\
\hline
\end{tabular}

Notes: $\mathrm{N}=391$. SD: standard deviation.

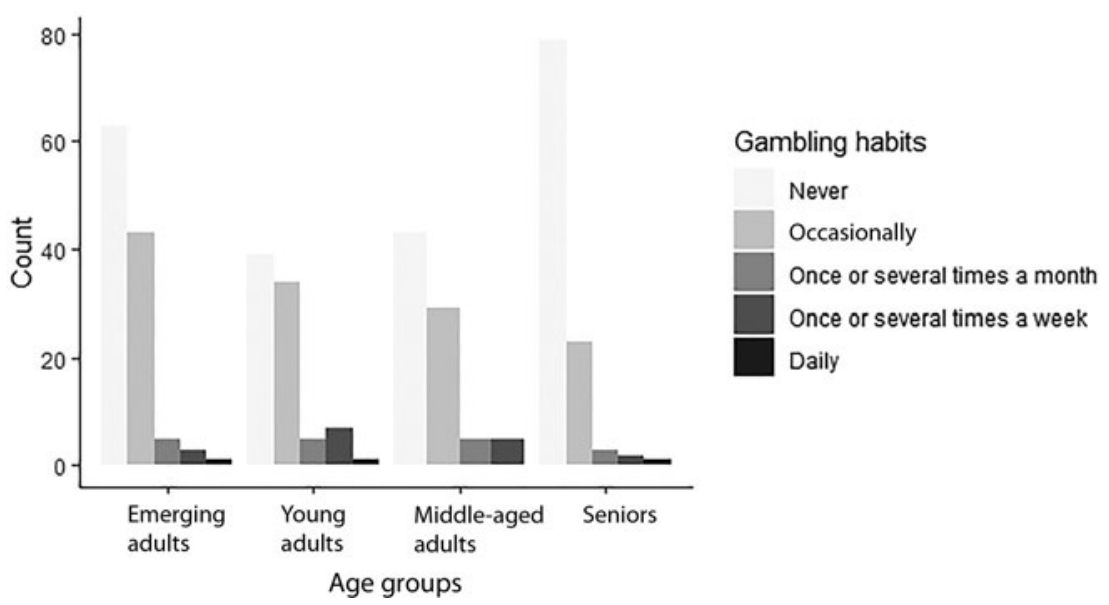

Figure 1. Gambling habits according to age.

showing that an illusion of control is present after two rounds (Ladouceur and Mayrand, 1984), we set the maximum number of rounds at ten.

\section{Risk-taking}

For a precise behavioural measure, we used the risk-taking formula validated by (Martinez et al., 2004) and used by Mouneyrac (2019) too:

$$
R T=\frac{[\text { Stake } \times(1-\text { Pile })]}{S W}
$$


where $R T=$ risk-taking in each round, $S W=$ state of wealth at the time of the bet in each round, Pile $=$ win probability for each round and Stake $=$ number of points wagered in each round.

The calculation of the mean risk took into account the number of rounds played by the participant and the reason for stopping. Thus, a different calculation was made depending on whether the participant had left the game or had no more points left. In the first case, a round was added, reasoning that the participant had stopped taking risks, so the risk-taking in the next round was zero. In the second case, we performed a standard mean calculation. Thus, the mean risk-taking if the participant had left the game was calculated as follows ( $n=$ number of rounds):

$$
R T_{\text {mean }}=\frac{R T_{1}+R T_{2}+\ldots+R T_{n}}{n+1}
$$

The risk-taking if the participant had no more points left was calculated as follows ( $n=$ number of rounds):

$$
R T_{\text {mean }}=\frac{R T_{1}+R T_{2}+\ldots+R T_{n}}{n}
$$

\section{Questionnaire 1}

This was an explicit measure of illusion of control via four questions inspired by Martinez et al. (2004) and Mouneyrac (2019). Participants were asked to indicate how much they agreed with each statement, by moving a cursor along a line from 0 (strongly disagree) to 100 (strongly agree):

- The game I just played is a game that involves skill.

- I have control over the results of the game I just played.

- It was possible to predict the outcome of the game I just played.

- The game I just played is based on chance (reversed item).

We verified the internal consistency of this measurement scale by calculating McDonald's omega (Béland et al., 2017) for all four items $(\omega=0.608)$. The McDonald's omega is interpreted in the same way as Cronbach's alpha but it is a more efficient alternative in terms of internal consistency (Dunn et al., 2014). Here, the omega remained below the consensual consistency threshold of 0.700 , but above 0.600, so still acceptable (Murphy and Davidshofer, and Nunally, in Peterson, 1995).

\section{Questionnaire 2}

This measured participants' TPs. We used the validated French-language version of the Zimbardo Time Perspective Inventory developed by Apostolidis and Fieulaine (2004). This is a 54-item questionnaire measuring five dimensions: negative past (ten items), positive past (seven items), fatalistic present (seven items), hedonistic present (18 items) and future (12 items). Respondents had to indicate their level of agreement with each statement on a five-point scale ranging from 'does not apply to me at all' to 'completely applies to me'. This French version of the questionnaire shows adequate psychometric properties: the test-retest fidelity indices of the five 
dimensions range from 0.68 to 0.78 , the internal consistency indices (Cronbach's alpha) are all greater than or equal to 0.70 .

We verified the internal consistency of this measurement scale in this study sample by calculating McDonald's omega (Béland et al., 2017) for each dimension: negative past $(\omega=0.883)$, positive past $(\omega=0.796)$, fatalistic present $(\omega=0.781)$, hedonistic present $(\omega=0.836)$ and future $(\omega=0.808)$.

\section{Procedure}

The online study consisted of three steps. After giving their consent, participants first completed the socio-demographic questionnaire with an anonymous code, providing information on age, sex, employment status, education level and gambling habits.

The second step was a computerised card game. As the gambling sequence was manipulated, the platform alternated between an ascending sequence (three losses, one gain, one loss, one loss, three gains, one loss, one loss, one loss) and a descending sequence (three gains, one loss, one gain, three losses, one gain, one loss) as the game progressed. In order to be as close as possible to an ecological situation, participants could quit the game at any time. There were three ways to end the game: the player had no more points left; the player completed all ten rounds; the player pressed the 'Exit the game' button.

Once the game was over, a link to the third step appeared. In this final step, we randomised the presentation of the illusion of control questionnaire (the order of items was also randomised) and the TP questionnaire.

\section{Results}

All analyses were performed with $\mathrm{R}$ (R Core Team, 2016) and the Rpackages psych (Revelle, 2016), because (Fox and Weisberg, 2011), multilevel (Bliese, 2016), ggplot2 (Wickham, 2009), ez (Lawrence, 2016), RcmdrMisc (Fox, 2016), dplyr (Wickham and François, 2016), lavaan (Rosseel, 2012) and semPlot (Epskamp, 2014).

We first analysed the influence of the gambling sequence and age on illusion of control and risk-taking. We then analysed the mediating effect of TP on the relationships between age and illusion of control, and between age and risk-taking.

\section{Influence of gambling sequence and age on illusion of control}

Despite a non-normal distribution of illusion of control, as tests indicated the homoscedasticity of variances and independence of observations (Norman, 2010), we ran a 2 (type of game: ascending versus descending sequence) $\times 4$ (age group: emerging adults, young adults, middle-aged adults, seniors) analysis of variance (ANOVA) (Figure 2). There was a significant main effect of age group on illusion of control, $F(3,382)=3.02, p=0.030, \eta^{2}=0.0231$. Pairwise comparisons with a Tukey correction indicated that emerging adults had a significantly greater illusion of control (mean $=29.51$, standard deviation $(S D)=22.34$ ) than either middle-aged adults $($ mean $=21.76, \mathrm{SD}=18.56), t(389)=-2.72, p_{\text {tukey }}=0.034$ or seniors $($ mean $=$ $22.80, \mathrm{SD}=19.40), t(389)=-2.44, p_{\text {tukey }}=0.071 \quad$ (trend towards significance). However, there was no effect of gambling sequence on illusion of control, 


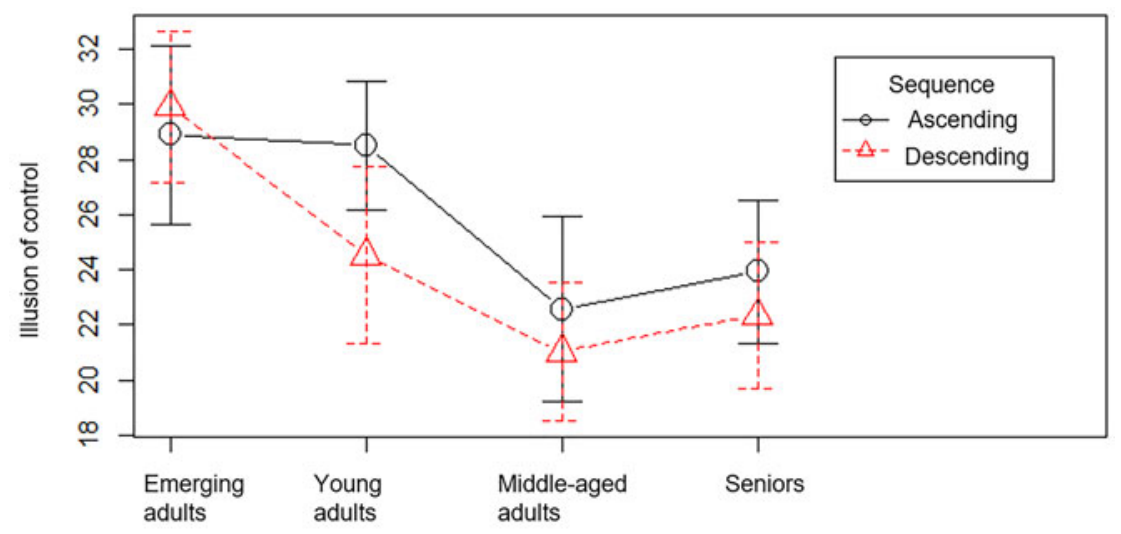

Age group

Figure 2. Mean illusion of control as a function of sequence and age. Note: The 95 per cent confidence intervals are shown.

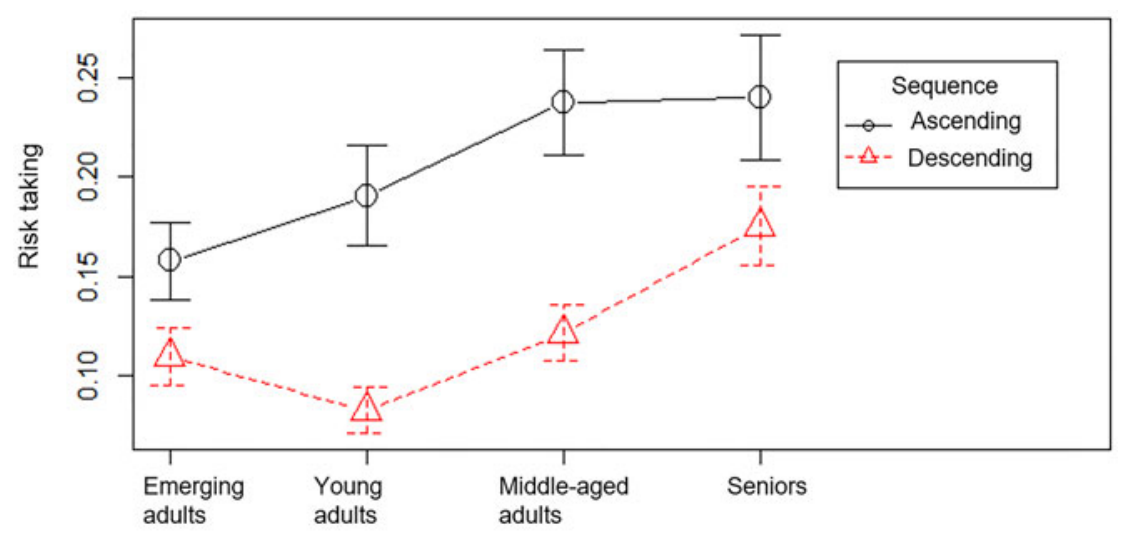

Age group

Figure 3. Mean risk-taking as a function of sequence and age group.

Note: The 95 per cent confidence intervals are shown.

$F(1,382)=0.63, p=0.428$ (not significant), and no interaction effect, $F(3,382)=0.26, p$ $=0.850$ (not significant).

\section{Effects of gambling sequence and age on risk-taking}

Although illusion of control and risk-taking were not correlated $(r=0.01, p=0.70$, not significant), we were interested in the influence of age and gambling sequence on risk-taking as an observable indicator of gambling behaviour. The distribution was not normal, but for the same reasons as for illusion of control, we ran a 2 (type of game: ascending versus descending sequence) $\times 4$ (age group: emerging adults, young adults, middle-aged adults, seniors) ANOVA (Figure 3). Analysis of the 
main effects indicated a significant influence of gambling sequence on risk-taking, $F(1,382)=31.96, p<0.001, \eta^{2}=0.0772$. All participants, regardless of age, took significantly more risks in the ascending condition (i.e. when they experienced losses first, then gains) (mean $=0.20, \mathrm{SD}=0.17$ ) than in the descending one (mean $=0.12, \mathrm{SD}=0.12$ ). There was also a main effect of age group on risk-taking, $F(3,382)=5.72, p<0.001$, $\eta^{2}=0.0430$. Regardless of gambling sequence, seniors took significantly more risks (mean $=0.20, \mathrm{SD}=0.18$ ) than either emerging adults (mean $=0.13, \mathrm{SD}=0.13$ ), $t(389)=3.66, p_{\text {tukey }}=0.002$ or young adults $($ mean $=0.14, \mathrm{SD}=0.14), t(389)=3.36$, $p_{\text {tukey }}=0.005$. The interaction effect was not significant, $F(3,382)=1.15, p=0.33$.

To test for the supposed mediating effect of TP on illusion of control and risktaking in gambling with ageing, we calculated a causal path model of this hypothesis. To assess this mediating effect, we used the resampling procedure (bootstrap), which has the advantage of not requiring either a normal distribution or a large sample (Efron, 2000). According to MacKinnon et al. (2004), this procedure seemed to produce the most accurate results, given the constraints associated with our sample: estimates of model parameters, significant at $p<0.05$, with significant confidence intervals (CIs) if they did not cross 0.

\section{Analysis of mediating effect of TP on relationship between age and illusion of control}

We used the maximum likelihood estimation method to perform the model evaluation. This method is based on different fit indices: a non-significant chi-square, a Root Mean Square Error of Approximation (RMSEA) below 0.06, a Comparative Fit Index (CFI) and a Tucker-Lewis Index (TLI) above 0.95, and a Standardised Root Mean Square Residual (SRMR) below 0.08 (Hooper et al., 2008). Our results, obtained with a bootstrap procedure $(\mathrm{N}=10,000)$ to compensate for data nonnormality, indicated good adequacy of the model, $\chi^{2}=2.85, p=0.241$, CFI $=0.99$, $\mathrm{TLI}=0.96, \mathrm{RMSEA}=0.03, \mathrm{SRMR}=0.02$ (Figure 4). Examination of the model parameters revealed that the total effect (i.e. sum of direct and indirect effects) was significant $(\beta=-0.14, p=0.016,95 \% \mathrm{CI}=-0.25,-0.03)$. However, none of the indirect effects was significant, so we cannot conclude that TPs had a mediating effect on illusion of control. Nevertheless, there was a direct positive effect of fatalistic present on illusion of control $(\beta=5.13, p=0.002,95 \% \mathrm{CI}=1.84,8.41)$ (Figure 4). A predominantly fatalistic-present TP therefore increased illusion of control. Results also showed a direct negative effect of age on illusion of control $(\beta=-0.12, p=0.039,95 \% \mathrm{CI}=-0.23,-0.003)$, confirming the results of the previous ANOVA showing that illusion of control decreased with age. There was also a negative effect of age on negative past $(\beta=-0.01, p<0.001,95 \% \mathrm{CI}=-0.014$, $-0.006)$ and hedonistic present $(\beta=-0.005, p=0.001,95 \% \mathrm{CI}=-0.008,-0.002)$ : ageing brings with it a less negative perception of the past and, more surprisingly, a reduced desire to enjoy the present time.

\section{Analysis of TP mediation of the relationship between age and risk-taking}

The results of the model evaluation (bootstrap, $\mathrm{N}=10,000$ ) indicated a satisfactory fit of the model to the data: $\chi^{2}=2.85, p=0.241, \mathrm{CFI}=0.99$, TLI $=0.97$, RMSEA $=$ 


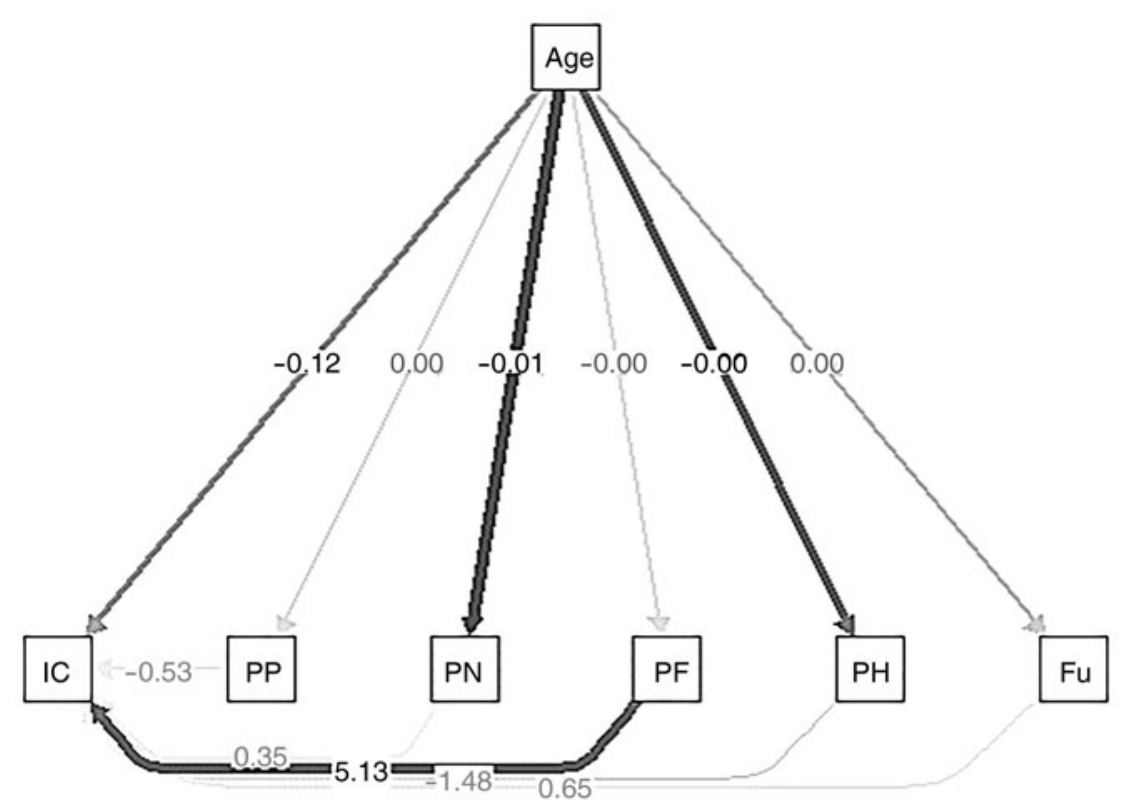

Figure 4. Illusion of control (IC) path model.

Notes: PP: positive past. PN: negative past. FP: fatalistic present. PH: hedonistic present. Fu: future.

$0.03, \mathrm{SRMR}=0.02$ (Figure 5). Examination of the model's parameters showed a significant total effect $(\beta=0.002, p<0.001,95 \% \mathrm{CI}=0.001,0.003)$ but, as with the illusion of control model, there was no significant indirect effect. We therefore could not conclude that TPs had a mediating effect on risk-taking. By contrast and in line with the results of the previous ANOVA, age positively influenced risktaking $(\beta=0.002, p<0.001,95 \% \mathrm{CI}=0.001,0.003)$, such that the older the participants, the more risks they took (Figure 5). Risk-taking was also positively influenced by the future TP $(\beta=0.04, p=0.021,95 \% \mathrm{CI}=0.005,0.07)$, suggesting that the dominance of future time leads individuals to take more risks. This result contradicts the literature on future TP, according to which a long-term rather than a short-term projection into the future implies reasoned regulation of present behaviour. Finally, this model confirmed the negative influence of age on negative past $(\beta=-0.01, p<0.001,95 \% \mathrm{CI}=-0.014,-0.006)$ and hedonistic present $(\beta=-0.005, p=0.001,95 \% \mathrm{CI}=-0.008,-0.002)$.

\section{Discussion}

Population ageing in post-industrialised countries constitutes a major challenge to ensure that their health and social systems are ready to make the most of this demographic shift. Seniors' gambling behaviour is rarely investigated, even though, in France, they are the heaviest consumers of gambling. To help reduce this gap, we tested, in older adults, the concepts behind compulsive gambling that are well known in the gambling literature. First, we hypothesised that the sequence of 


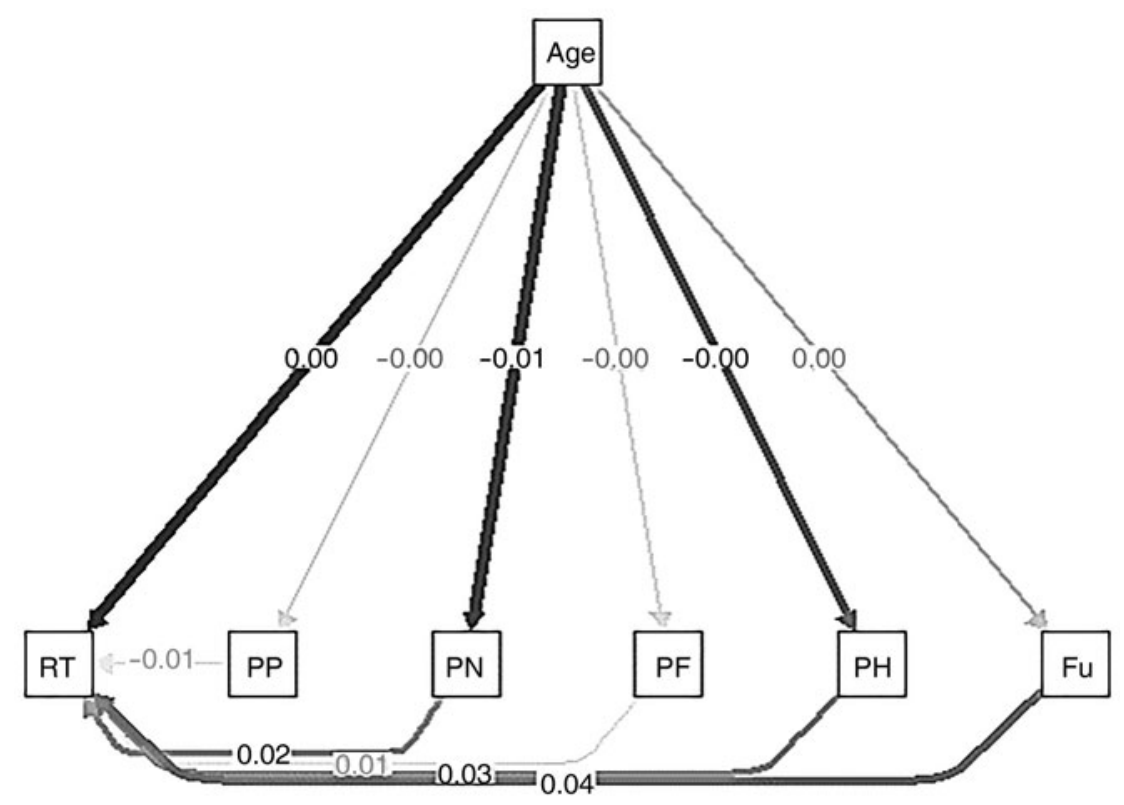

Figure 5. Risk-taking (RT) path model.

Notes: PP: positive past. PN: negative past. FP: fatalistic present. PH: hedonistic present. Fu: future.

outcomes has an age-related influence on both illusion of control and risk-taking. We then predicted that TP would have a mediating effect on both these relationships. Our hypotheses were partially confirmed: we found no significant effect of the sequence of outcomes on illusion of control, but a significant effect on risktaking. Participants took significantly more risks in a loss (versus gain) situation. Thus, suffering losses before achieving gains leads gamblers to take more risks than if the gains precede the losses (e.g. lottery gamblers presumably experience many losses before enjoying what are generally small gains). Our results could serve as the basis for formulating primary and secondary preventive recommendations focusing on the cumulative amount of losses compared to the amount of gains. More specifically, seniors took more risks than younger people. At first glance, this risk-taking may seem contradictory, given the more pronounced loss aversion among seniors (Mather et al., 2012). The certainty effect (Kahneman and Tversky, 1979) helps to make sense of this result. As gambling is a risky and uncertain situation where one is likely to lose, and since older people have a greater aversion to loss than young people, it is logical that they should take more risks than younger people do. One constant emerged from our analyses: even though illusion of control decreased with age, risk-taking increased. These results therefore call into question the positive correlation established by Martinez et al. (2005) between increased illusion of control and increased risk-taking, at least for seniors. We must therefore review the influence of this cognitive distortion in gambling.

While we cannot conclude that TP has a mediating effect on either illusion of control or risk-taking, the direct effects of some TP dimensions justify further research in this area. The link between a high score on the fatalistic-present dimension and high 
illusion of control is surprising, as the fatalistic present refers to a view whereby events are dictated by uncontrollable forces and a tendency to resignation. It is a confusing influence if we remain at a semantic level where believing in uncontrollable forces increases illusion of control. The positive influence of this TP on illusion of control therefore raises several questions, such as whether fatalism fosters such a belief in luck (by definition uncontrollable) that individuals paradoxically think they are so lucky that it increases their illusion of control. Individuals who perceive the present to be determined by uncontrollable forces would believe that these forces serve their interests. Such individuals rely on luck, and this pushes them to manifest an illusion of secondary control (Ejova et al., 2015). We cannot answer this question without rethinking the measurement, and perhaps even the very definition, of illusion of control, as this concept remains highly controversial, even though many studies have examined it in recent decades (Masuda et al., 2002).

Our results highlight the problem of measuring illusion of control, as this concept has several, sometimes conflicting, aspects, such as belief in specific abilities and the negation of chance. Then again, the dimensions of illusion of control may not be contradictory, as individuals may believe in chance but also believe that this chance is favourable to them because they are lucky people. Work on defining and constructing items for a reliable and accurate multi-dimensional scale to measure illusion of control is needed if we are to have a better understanding of this cognitive distortion. How we measure illusion of control, beyond its use in gambling research, is a crucial issue. A better measurement of illusion of control would enhance its study in all areas where it is involved (e.g. gambling, driving, sports). Including TPs as behavioural indicators and cognitive and emotional style acting on attitudes (Epel et al., 1999) in this research is a new and, given the current results, promising way of considering illusion of control in gambling.

At first glance, the surprising finding that future TP has a positive influence on risktaking would appear to contradict the literature (environment and health) on the role of TP in risky behaviours. However, this future TP may be biased by the illusion of gain. If individuals are able to project themselves into the long term by imagining that they have won a wager, they may be liable to take more risks (in order to realise this imaginary future) than individuals with a reduced future TP who therefore consider more immediate losses. The question of the valence (positive versus negative) of the future TP, in relation to its depth, therefore merits investigation.

Our results on the effect of age on TPs, and more specifically the negative influence of age on the negative past, suggest that the older people become, the less negatively they perceive the past. Although this finding addresses a different dimension of TP, it is consistent with the work of Menahem (cited by Nuttin, 1979) suggesting that positive emotional attitudes towards the past increase with age. By contrast, the negative influence of age on the hedonistic present, suggesting that the older people become, the less they want to enjoy a present perceived of as ephemeral, questions our naïve representations of ageing and nuances the findings of Cameron (cited by Nuttin, 1979). These authors noted that the predominance of the present is affirmed with age to the detriment of a future TP. We do not in any way claim to invalidate the conclusions in the literature, nor would the absence of an influence of age in our results on the fatalistic-present or future TP allow us to do so. However, the existence of contextual feedback on TP may explain these 
contradictory results. The very specific gambling situation in which the participants were placed may have influenced their responses to the TP questionnaire. To avoid discouraging the participants from the start and biasing their risk-taking, we chose to administer this questionnaire after they had played the game. Nevertheless, even if it meant greater experimental mortality, it would be interesting to randomise the timing of the TP questionnaire and the game. In addition, the context effect could be manipulated in future research on TP. The question of TP sensitivity to context could also be explored in terms of the type of gambling elicited and participants' degree of autonomy. The online version of the game may not have been suited to a population of seniors, and using the internet inevitably meant that we did not reach every segment of our population of interest. It would therefore be useful to replicate the experiment with a different, more traditional form of gambling. One limitation of this study is the representativeness of our sample. The results should be taken as a starting point for addressing the issues of illusion of control and risktaking and time perspectives in senior gambling. Future research may examine cultural and other variability on these matters.

Looking at TP in the form of profiles seems to us to be an interesting avenue of research in order to evaluate their combined influences on gambling behaviours. Profiles of TP would make it possible to summarise the different types of relationship that an individual has with the temporalities likely to influence his or her behaviours. They would also shed light on the latent emotional aspects interacting with age. The work on TP (Nuttin, 1979; Rönnlund et al., 2017) indicates that TP changes with age, so a profile specific to seniors can be hypothesised, which is useful for developing targeted gambling prevention measures. Indeed, present results would invite a focus on a reminder of losses as negative past events, specifically for seniors, who tend to perceive the past less negatively than younger people. Future research is needed to test these hypotheses.

Financial support. The study has not been funded by external funds or grants.

Conflict of interest. The authors declare no conflicts of interest.

\section{References}

Abbott M, Binde P, Clark L, Hodgins D, Johnson M, Manitowabi D, Quilty L, Spangberg J, Volberg R, Walker D and Williams R (2018) Conceptual Framework of Harmful Gambling: An International Collaboration, 3rd Edn. Guelph, Canada: Gambling Research Exchange Ontario (GREO).

Apostolidis T and Fieulaine N (2004) Validation française de l'échelle de temporalité. Revue Européenne de Psychologie Appliquée/European Review of Applied Psychology 54, 207-217.

Ariyabuddhiphongs V (2012) Older adults and gambling: a review. International Journal of Mental Health and Addiction 10, 297-308.

Barrault S and Varescon I (2012) Distorsions cognitives et pratique de jeu de hasard et d'argent: état de la question. Psychologie française 57, 17-29.

Beitz KM, Salthouse TA and Davis HP (2014) Performance on the Iowa Gambling Task: from 5 to 89 years of age. Journal of Experimental Psychology: General 143, 1677-1689.

Béland S, Cousineau D and Loye N (2017) Utiliser le coefficient omega de McDonald à la place de l'alpha de Cronbach. McGill Journal of Education/Revue des sciences de l'éducation de McGill 52, 791-804.

Binde P (2013) Why people gamble: a model with five motivational dimensions. International Gambling Studies 13, 81-97. 
Blaszczynski A and Nower L (2002) A pathways model of problem and pathological gambling. Addiction 97, 487-499.

Bliese P (2016) multilevel: Multilevel Functions.https://cran.r-project.org/web/packages/multilevel/multilevel.pdf.

Calado F and Griffiths MD (2016) Problem gambling worldwide: an update and systematic review of empirical research (2000-2015). Journal of Behavioral Addictions 5, 592-613.

Costes J-M, Pousset M, Eroukmanoff V, Le Nezet O, Richard J-B, Guignard R, Beck F and Arwidson P (2011) Les niveaux et pratiques des jeux de hasard et d'argent en 2010. Tendances, OFDT (77), 1-8.

Costes J-M, Richard J-B, Eroukmanoff V, Le Nézet $O$ and Philippon A (2020) Les Français et les jeux d'argent et de hasard. Résultats du Baromètre de Santé publique France 2019. Tendances, OFDT (138), $1-6$.

Demarque C, Monaco GL, Apostolidis T and Guimelli C (2011) Socialisation, perspectives temporelles et implication personnelle: une étude dans le champ de l'environnement. Les Cahiers Internationaux de Psychologie Sociale 92, 351.

Denburg NL, Tranel D and Bechara A (2005) The ability to decide advantageously declines prematurely in some normal older persons. Neuropsychologia 43, 1099-1106.

Desai RA, Maciejewski PK, Dausey DJ, Caldarone BJ and Potenza MN (2004) Health correlates of recreational gambling in older adults. American Journal of Psychiatry 161, 1672-1679.

Donati MA, Sottili E, Morsanyi K and Primi C (2019) Time perspectives and gambling in adolescent boys: differential effects of present- and future-orientation. Journal of Gambling Studies 35, 107-124.

Dowling NA, Youssef GJ, Jackson AC, Pennay DW, Francis KL, Pennay A and Lubman DI (2016) National estimates of Australian gambling prevalence: findings from a dual-frame omnibus survey. Addiction 111, 420-435.

Dunn TJ, Baguley T and Brunsden V (2014) From alpha to omega: a practical solution to the pervasive problem of internal consistency estimation. British Journal of Psychology 105, 399-412.

Efron B (2000) The bootstrap and modern statistics. Journal of the American Statistical Association 95, 1293.

Ejova A, Delfabbro PH and Navarro DJ (2015) Erroneous gambling-related beliefs as illusions of primary and secondary control: a confirmatory factor analysis. Journal of Gambling Studies 31, 133-160.

Ejova A, Navarro DJ and Delfabbro PH (2013) Success-slope effects on the illusion of control and on remembered success-frequency. Judgment and Decision Making 8, 498.

Epel ES, Bandura A and Zimbardo PG (1999) Escaping homelessness: the influences of self-efficacy and time perspective on coping with homelessness. Journal of Applied Social Psychology 29, 575-596.

Epskamp S (2014) semPlot: Path Diagrams and Visual Analysis of Various SEM Packages' Output. https:// cran.r-project.org/web/packages/semPlot/semPlot.pdf).

Fein G, McGillivray S and Finn P (2007) Older adults make less advantageous decisions than younger adults: cognitive and psychological correlates. Journal of the International Neuropsychological Society 13, 480-489.

Fox J (2016) RcmdrMisc: R Commander Miscellaneous Functions.https://cran.r-project.org/web/packages/ semPlot/semPlot.pdf.

Fox J and Weisberg S (2011) An $\{R\}$ Companion to Applied Regression. Thousand Oaks, CA: Sage.

Gana K, Klein V, Saada Y and Trouillet R (2013) Perspectives temporelles et satisfaction de vie chez les personnes âgées: test de l'effet médiateur du sentiment d'auto-efficacité. Revue Européenne de Psychologie Appliquée/European Review of Applied Psychology 63, 49-57.

Giroux I, Ferland F, Savard C, Jacques C, Brochu P, Nadeau D, Landreville P and Sévigny S (2016) Les joueurs sans problème de jeu de 55 ans et plus: événements, conséquences et caractéristiques structurelles et environnementales influençant les habitudes de jeu. Journal of Gambling Issues 32, 89-110.

Goodie AS, Fortune EE and Shotwell JJ (2019) Cognitive distortions in disordered gambling. In Heinz A, Romanczuk-Seiferth N and Potenza MN (eds), Gambling Disorder. Cham, Switzerland: Springer International Publishing, pp. 49-71.

Granero R, Jiménez-Murcia S, del Pino-Gutiérrez A, Mena-Moreno T, Mestre-Bach G, Gómez-Peña M, Moragas L, Aymamí N, Giroux I, Grall-Bronnec M, Sauvaget A, Codina E, Vintró-Alcaraz C, Lozano-Madrid M, Camozzi M, Agüera Z, Martín-Romera V, Sánchez-González J, Casalé G, Sánchez I, López-González H, Munguía L, Valenciano-Mendoza E, Mora B, Baenas-Soto I, 
Menchón JM and Fernández-Aranda F (2020) Gambling phenotypes in older adults. Journal of Gambling Studies 36, 809-828.

Grant JE, Kim SW, Odlaug BL, Buchanan SN and Potenza MN (2009) Late-onset pathological gambling: clinical correlates and gender differences. Journal of Psychiatric Research 43, 380-387.

Guillou Landreat M, Cholet J, Grall Bronnec M, Lalande S and Le Reste JY (2019) Determinants of gambling disorders in elderly people - a systematic review. Frontiers in Psychiatry 10, 837.

Guillou Landreat M, Le Reste JY, Théréné-Mouden C, Caillon J, Cholet J and Grall Bronnec M (2016) Les jeux de hasard et d'argent chez les sujets âgés. Soins Gérontologie 5237, 1-48.

Hagen B, Nixon G and Solowoniuk J (2005) Stacking the odds: a phenomenological study of non-problem gambling in later life. Canadian Journal on Aging/La Revue canadienne du vieillissement 24, 433-442.

Hilbrecht M, Baxter D, Abbott M, Binde P, Clark L, Hodgins DC, Manitowabi D, Quilty L, Spångberg J, Volberg R, Walker D and Williams RJ (2020) The conceptual framework of harmful gambling: a revised framework for understanding gambling harm. Journal of Behavioral Addictions 9, 190-205.

Hirsch P (2000) Seniors and Gambling: Exploring the Issues: Summary Report. Canada: Alberta Alcohol and Drug Abuse Commission.

Hodgins DC and Engel A (2002) Future time perspective in pathological gamblers. Journal of Nervous and Mental Disease 190, 775-780.

Hooper D, Coughlan J and Mullen M (2008) Structural equation modelling: guidelines for determining model fit. Electronic Journal of Business Research Methods 6, 53-60.

INSEE (2016) Les comptes de la nation en 2015, base 2010. France: Insee Résultats.https://www.insee.fr/fr/ statistiques/2121563? sommaire $=2383694$.

Kahneman D and Tversky A (1979) Prospect theory: an analysis of decision under risk. Econometrica 47, 263-291.

Kerber CS, Black DW and Buckwalter K (2008) Comorbid psychiatric disorders among older adult recovering pathological gamblers. Issues in Mental Health Nursing 29, 1018-1028.

Keren GB and Wagenaar WA (1985) On the psychology of playing blackjack: normative and descriptive considerations with implications for decision theory. Journal of Experimental Psychology: General 114, 133.

Kruger DJ, Reischl T and Zimmerman MA (2008) Time perspective as a mechanism for functional developmental adaptation. Journal of Social, Evolutionary, and Cultural Psychology 2, 1-22.

Ladouceur R and Mayrand M (1984) Evaluation of the 'illusion of control': type of feedback, outcome sequence, and number of trials among regular and occasional gamblers. Journal of Psychology 117, 37-46.

Langer EJ (1975) The illusion of control. Journal of Personality and Social Psychology 32, 311-328.

Langer EJ and Roth J (1975) Heads I win, tails it's chance: the illusion of control as a function of the sequence of outcomes in a purely chance task. Journal of Personality and Social Psychology 32, 951-955.

Lawrence MA (2016) ez: Easy Analysis and Visualization of Factorial Experiments.

Löckenhoff CE (2018) Aging and decision-making: a conceptual framework for future research - a minireview. Gerontology 64, 140-148.

Luo H and Ferguson M (2017) Gambling among culturally diverse older adults: a systematic review of qualitative and quantitative data. International Gambling Studies 17, 290-316.

MacKinnon DP, Lockwood CM and Williams J (2004) Confidence limits for the indirect effect: distribution of the product and resampling methods. Multivariate Behavioral Research 39, 99-128.

Martinez F (Gaffié B and Le Floch V as co-authors) (2004) Lien entre l'annonce du résultat d'autrui, l'illusion de contrôle et la prise de risque dans un jeu de hasard et d'argent (Doctoral thesis). Le Mirail, Toulouse, France.

Martinez F, Le Floch V and Gaffié B (2005) Lien entre perception de contrôle et prise de risque dans un jeu de hasard: Quand l'annonce d'un gain d'autrui intervient. Revue internationale de psychologie sociale 18, 129-151.

Masuda S, Sakagami T and Hirota S (2002) Illusion of control: consideration of the experimental manipulations and measurement methods. Japanese Psychological Review 45, 125-140.

Mather M, Mazar N, Gorlick MA, Lighthall NR, Burgeno J, Schoeke A and Ariely D (2012) Risk preferences and aging: the 'certainty effect' in older adults' decision making. Psychology and Aging 27, 801.

Matute H (1995) Human reactions to uncontrollable outcomes: further evidence for superstitions rather than helplessness. Quarterly Journal of Experimental Psychology: B. Comparative and Physiological Psychology 48, 142. 
McNeilly DP and Burke WJ (2001) Gambling as a social activity of older adults. The international journal of aging and human development 52, 19-28.

Medeiros GC, Leppink E, Yaemi A, Mariani M, Tavares H and Grant J (2015) Gambling disorder in older adults: a cross-cultural perspective. Comprehensive Psychiatry 58, 116-121.

Mouneyrac A (2019) Messages de prévention promouvant le Jeu responsable: une injonction paradoxale dans les jeux de hasard et d'argent (Doctoral thesis). Toulouse 2, Toulouse, France.

Norman G (2010) Likert scales, levels of measurement adn the "laws" of statistics. Advances in Health Sciences Education 15, 625-632.

Nuttin J (1979) La perspective temporelle dans le comportement humain. In Du temps biologique au temps psychologique/Symposium de l'Association de psychologie scientifique de langue française, Poitiers, 1977. Paris: Presses universitaires de France.

Observatoire Des Jeux (2016) Une première cartographie des pratiques de jeu d'argent et de hasard. Les notes de l'observatoire des jeux No. 7. https://www.economie.gouv.fr/files/files/directions_services/observatoire-des-jeux/Note_ODJ_7.pdf.

Pachur T, Mata R and Hertwig R (2017) Who dares, who errs? Disentangling cognitive and motivational roots of age differences in decisions under risk. Psychological Science 28, 504-518.

Parke A, Griffiths M, Pattinson J and Keatley D (2018) Age-related physical and psychological vulnerability as pathways to problem gambling in older adults. Journal of Behavioral Addictions 7, 137-145.

Peterson RA (1995) Une méta-analyse du coefficient alpha de Cronbach. Recherche et Applications en Marketing (French Edition) 10, 75-88.

Pietrzak RH, Molina CA, Ladd GT, Kerins GJ and Petry NM (2005) Health and psychosocial correlates of disordered gambling in older adults. American Journal of Geriatric Psychiatry 13, 510-519.

Pittet Y-K, Simon O and Besson J (2014) Jeu excessif et personnes âgées. La gazette médicale, 10-13.

Poupard M (2013) Problèmes de jeu chez les aînés: l'influence perçue des événements de vie (Doctoral thesis). Université Laval, Québec City, Canada.

Presson PK and Benassi VA (1996) Illusion of control: a meta-analytic review. Journal of Social Behavior and Personality 11, 493-510.

R Core Team (2016) R: A Language and Environment for Statistical Computing. Vienna: R Foundation for Statistical Computing.

Revelle W (2016) psych: Procedures for Personality and Psychological Research. Evanston, IL: Northwestern University.

Rogers P (1998) The cognitive psychology of lottery gambling: a theoretical review. Journal of Gambling Studies 14, 111-134.

Rönnlund M, Åström E and Carelli MG (2017) Time perspective in late adulthood: aging patterns in past, present and future dimensions, deviations from balance, and associations with subjective well-being. Timing \& Time Perception 5, 77-98.

Rosseel Y (2012) \{lavaan\}: an $\{\mathrm{R}\}$ package for structural equation modeling. Journal of Statistical Software 48, 1-36.

Skinner W and Turner NE (2018) Gambling on an aging population. Journal of Gambling Issues 39, 1-5.

Stefan S and David D (2013) Recent developments in the experimental investigation of the illusion of control. A meta-analytic review. Journal of Applied Social Psychology 43, 377-386.

Stolarski M, Fieulaine N and van Beek W (eds) (2015) Time Perspective Theory; Review, Research and Application: Essays in Honor of Philip G. Zimbardo. Cham, Switzerland: Springer International Publishing.

Strough J, Bruin WB de and Peters E (2015) New perspectives for motivating better decisions in older adults. Frontiers in Psychology 6, 783.

Subramaniam M, Wang P, Soh P, Vaingankar JA, Chong SA, Browning CJ and Thomas SA (2015) Prevalence and determinants of gambling disorder among older adults: a systematic review. Addictive Behaviors 41, 199-209.

Tira C and Jackson AC (2015) Exploring the gray areas: senior gamblers' perceptions of what is and what isn't gambling. Journal of Gambling Issues, Tira C and Jackson AC, 24-44.

Tse S, Hong S-I, Wang C-W and Cunningham-Williams RM (2012) Gambling behavior and problems among older adults: a systematic review of empirical studies. Journals of Gerontology: Psychological Sciences and Social Sciences 67B, 639. 
Tymula A, Belmaker LAR, Ruderman L, Glimcher PW and Levy I (2013) Like cognitive function, decision making across the life span shows profound age-related changes. Proceedings of the National Academy of Sciences 110, 17143-17148.

Van Brunschot E Gibbs (2009) Gambling and Risk Behaviour: A Literature Review. Canada: Alberta Gambling Research Institute.

van der Maas M, Mann RE, McCready J, Matheson FI, Turner NE, Hamilton HA, Schrans T and Ialomiteanu A (2017) Problem gambling in a sample of older adult casino gamblers: associations with gambling participation and motivations. Journal of Geriatric Psychiatry and Neurology 30, 3-10.

Wainstein L, Grall-Bronnec M and Venisse J-L (2008) Caractéristiques des conduites de jeux chez le sujet âgé. NPG Neurologie - Psychiatrie - Gériatrie 8, 17-22.

Wickham H (2009) ggplot2: Elegant Graphics for Data Analysis. New York, NY: Springer-Verlag.

Wickham H and François R (2016) dplyr: A Grammar of Data Manipulation.

World Health Organization (2015) Vieillissement et santé. Geneva: World Health Organization. Available at http://www.who.int/mediacentre/factsheets/fs404/fr/.

Zimbardo PG and Boyd JN (1999) Putting time in perspective: a valid, reliable individual-differences metric. Journal of Personality and Social Psychology 77, 1271-1288. 


\section{Appendix}

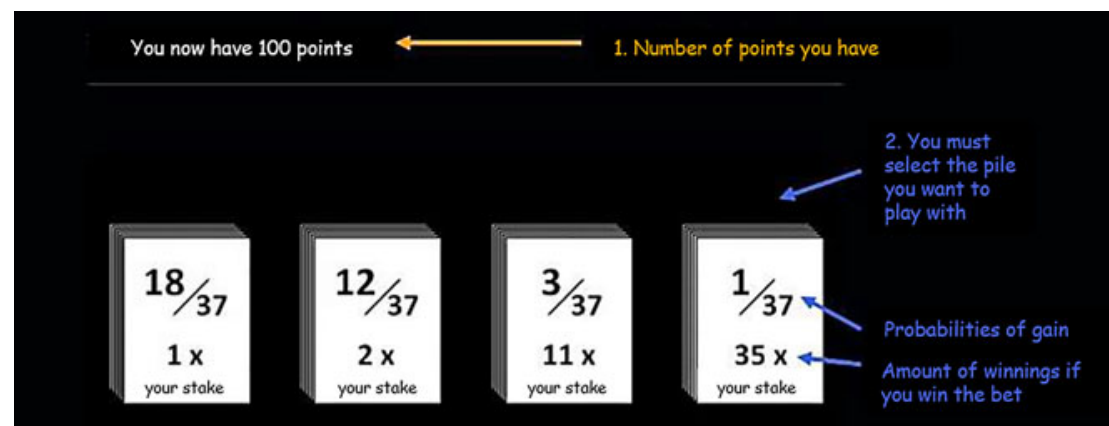

Stake

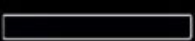

4 3. Enter the amount you wish to bet

Launch the bet

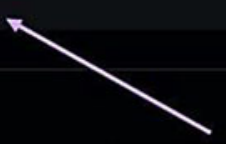

4. Once you place the bet the top card of the chosen pile will be returned by the application

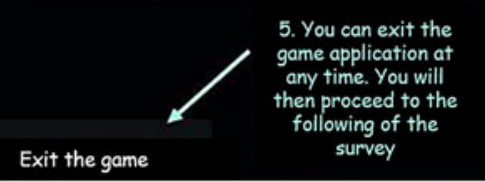

Cite this article: Fontaine M, Floch VL, Lemercier C (2023). Gambling and ageing: less illusion but more risk. Ageing \& Society 43, 556-575. https://doi.org/10.1017/S0144686X21000714 